\title{
Non-market Valuation of Tiya Megalithic World Cultural Heritage of Ethiopia, Application of Travel Cost and Contingent Valuation Methods
}

\author{
Hayatu Mude ${ }^{1}$, Abebe Belachew ${ }^{2}$, Mekonnen Bersisa ${ }^{3}$ \\ ${ }^{1}$ Department of Economics, Wolkite University, Wolkite, Ethiopia \\ ${ }^{2}$ Economic, Social and M\&E Consultant, Wolkite, Ethiopia \\ ${ }^{3}$ Department of Economics, Addis Ababa University, Addis Ababa, Ethiopia
}

Email address:

hayatumude3@gmail.com (H. Mude), abebeblchw@gmail.com (A. Belachew), mbersisa@gmail.com (M. Bersisa)

To cite this article:

Hayatu Mude, Abebe Belachew, Mekonnen Bersisa. Non-market Valuation of Tiya Megalithic World Cultural Heritage of Ethiopia, Application of Travel Cost and Contingent Valuation Methods. American Journal of Environmental and Resource Economics. Vol. 5, No. 3, 2020, pp. 59-70. doi: 10.11648/j.ajere.20200503.13

Received: March 21, 2019; Accepted: January 15, 2020; Published: September 10, 2020

\begin{abstract}
The main purpose of this study is to estimate the total economic value of Tiya megalithic world cultural heritage site using non-market valuation methods of Travel Cost Method (TCM) and Contingent Valuation Method (CVM). The study uses Individual Travel Cost Method to estimate the use value and the Double Bounded Contingent Valuation Method to investigate the mean Willingness to Pay for the nonuse value of the Tiya MWCH site. The truncated Poisson regression method (TPRM) was employed to derive the demand function for the use value of Tiya MWCH site and the bivariate probit model were used to estimate the nonuse value of Tiya $\mathrm{MWCH}$ site. The regression result showed that travel cost, monthly income, total travel time, sex, family size, household head, purpose of visit, membership in any environmental group and knowledge are important determinants of the recreational demand of the site. The result of the study also showed that the potential annual use value of the Tiya MWCH site was estimated to be 9,615,508.00 ETB per year and the nonuse value (one time contribution of community residents of Tiya town) of the site is $64,494.20$ ETB. Finally, we recommend that to maintenances and maximize the benefits that can be derived from the Tiya MWCH site.
\end{abstract}

Keywords: Non-market Valuation, Cultural Heritage, Tiya Megalithic Site, Contingent Valuation Method, Individual Travel Cost Method

\section{Introduction}

The World Travel \& Tourism Council (WTTC) estimates that the Travel and Tourism sector now accounts for $9.5 \%$ of global GDP, a total of US\$ 7 trillion, and $5.4 \%$ of world exports. Encouraging the development of the Travel and Tourism sector is even more important as the Travel and Tourism industry continues to play a key role as a driver of growth and job creation, growing at 4\% in 2014 and providing 266 million jobs, directly and indirectly. This means that the industry now accounts for one in 11 jobs on the planet, a number that could even rise to one in 10 jobs by 2022, according to the WTT [1]. According to [2], Cultural and heritage tourism is defined as travel directed toward experiencing the arts, heritage and activities that truly represent the stories and people of the past and present. Cultural heritage tourism is one of the best parts of the tourism industry, and is a more powerful economic development tool.

As in many developing countries, population pressure, environmental degradation, poverty and global warming endanger Ethiopia's natural and cultural heritage. However, the country has not generated enough revenue from the cultural heritage sites sector, which incorporates varieties of tourist attraction areas. This is due to lack of rigorous empirical studies on visitors' valuation of the historical sites in addition to other complex socio-economic problems [3].

A diverse set of economic valuation methods, therefore, will be needed to span this gap between private/market values and public/non market values [4]. The absence of a price means that we cannot observe values for cultural 
heritage goods directly. Instead, we must, like detectives, look for clues that tell us something about value indirectly. Non-market valuation is a term used to describe a variety of techniques for looking for and interpreting these clues about value for goods that are not traded in markets [5].

Ethiopia's cultural industry is perhaps one of the oldest in the world and is exceptionally diverse. Moreover, nine of Ethiopia's cultural and natural heritage sites are listed on UNESCO'S World Heritage Site attesting to the outstanding universal value of Ethiopia's heritage [3]. Tiya Megalithic World Heritage Site is one of the first twelve sites of Ethiopia to be inscribed by UNESCO on the World Heritage List in 5 September 1980. Tiya is among the most important of the roughly 160 archaeological sites discovered so far in the Soddo area, south of Addis Ababa at $86 \mathrm{~km}$. Therefore investigate and promoting this wonderful cultural heritage to the world is very important in order to increase its multidimensional benefit gained.

Currently Tiya megalithic world cultural heritage site is endangered by manmade and natural externalities, Lack of appropriate funds and skilled personnel significantly contribute to the deterioration of the site. Which are; even if it had been registered by UNESCO since 1980, there are a lots of problems such as; the site start to collect any form of earnings in September 2007(by using the opportunity of the Ethiopian millennium celebration) therefore it doesn't have enough financial resource, The area fenced with wooden post and wire mesh (it reduce the number of local visitors to pay the entrance fee because they can see far apart), some of the monuments and stelae are fall off and some of them are tending to fall; as a result, they lose their originality and their architectural attractiveness, there is no guest house, restaurant and other entertainment services (like, DSTV room, tennis table...etc. As a result the site should be preserve from these problems and it needs curious improvement. Therefore in order to address these issues and taking the advantages, here we are implement both contingent valuation method (CVM) and travel cost method (TCM) to estimate and analyze the conservation as well as economic values of Tiya megalithic world cultural heritage site in Ethiopia.

The mainly the objective of this study is to estimate total economic value of Tiya megalithic world cultural heritage site of Ethiopia by using TCM and CVM. Specifically to identify factors that determines respondents' maximum willingness to pay for conservation and protection of the Tiya megalithic cultural heritage.

\section{Research Methodology}

\subsection{Description of the Study Area}

The study was conducted in a small village town called Tiya. It is found in the central Ethiopia, situated in the Guraghe Zone of the Southern Nations, Nationalities, and Peoples Regional state at $84 \mathrm{~km}$ away from Addis Ababa. They are numerous, and contain large numbers of monuments. Megalithic sites exist in other African countries, particularly Senegal, Mali, and Nigeria, but the quality and Originality of the Ethiopian monuments merit particular attention.

Map of Tiya World Cultural Heritage Site

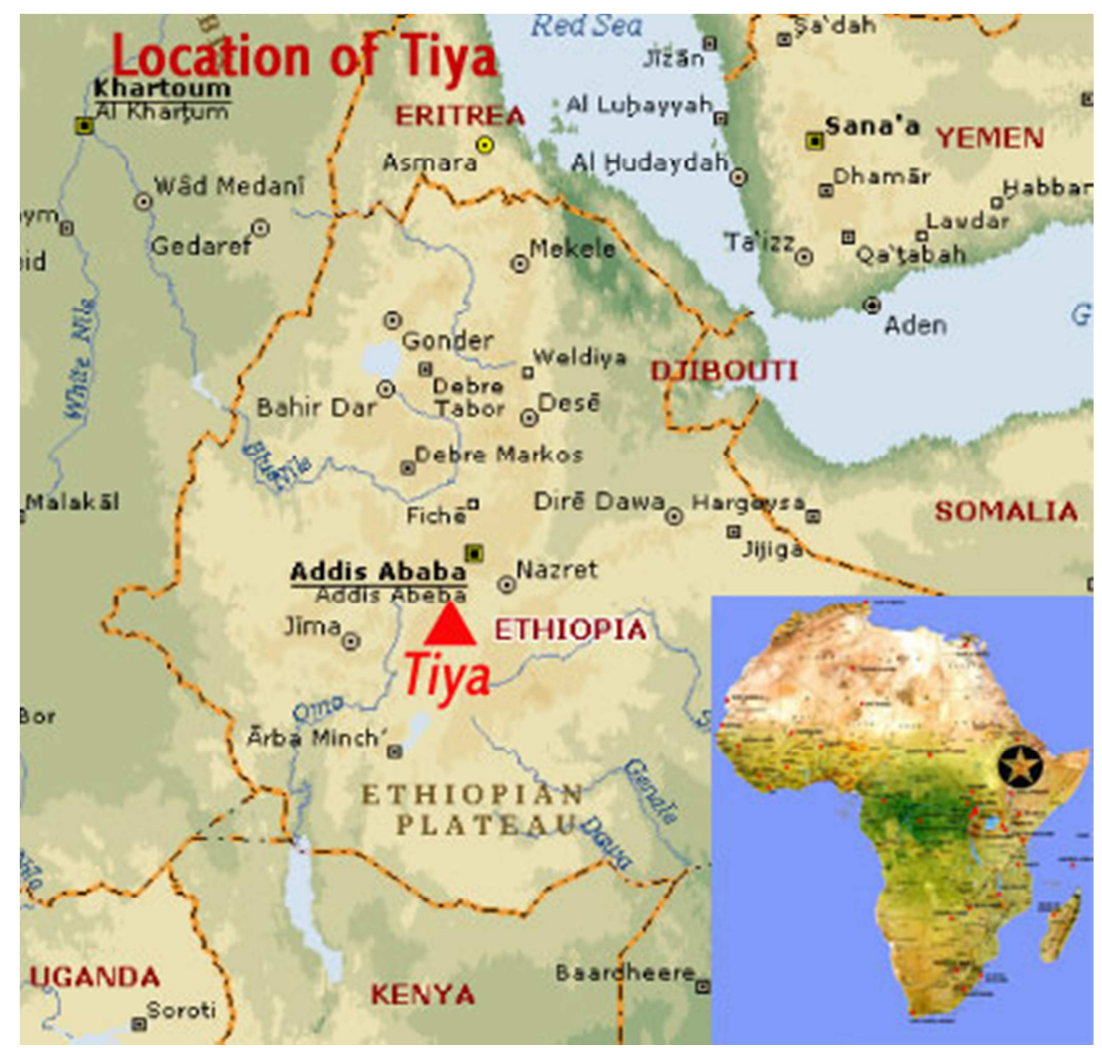

Figure 1. Location Map of Tiya World Heritage Site. 
Geographically, Tiya Megalithic World Heritage Site is situated on a latitude and longitude of $8^{\circ} 26^{\prime} \mathrm{N} 38^{\circ} 37^{\prime} \mathrm{E} 8.433^{\circ} \mathrm{N}$ $38.617^{\circ} \mathrm{E}$. Tiya town is also belongs to "Weina Dega" or subtropical climatic zonation within the five traditional climatic zonation of Ethiopia known as Wirch, Dega, Weinadega, Kolla and Bereha. The mean annual temperature of the town is about $17.6^{\circ} \mathrm{C}$ and the Mean annual rainfall recorded from Buie meteorological station is $1,012 \mathrm{~mm}$.

\subsection{Source of Data and Method of Data Collection}

The primary data utilize in the descriptive and empirical analyses of this study was collected from four woredas which found in the surrounding of the park using one of the probability sampling techniques which is multi-stage sampling, the households in six villages (Kebeles) were selected by using Simple Random Sampling, those selected kebeles were four woreda administration of the SNNP Regional State of Ethiopia The data was collect through CV survey questionnaire that the Researcher was design and then organizes in a way that could capture all relevant information by employing face-to-face data collection techniques. A double bounded dichotomous choice with follow up format was used to elicit respondents' WTP for conservation of Gibe Sheleko National park in terms of cash or labor force time contribution. In addition, information regarding the socioeconomic characteristics of households' was collected. Secondary data will collect from books, articles, magazines and source document about the park from Gibe Sheleko National park office, Gurage Zone forest and environment office.

\subsection{Sample Design and Procedures}

In this study, probability and non-probability type of sampling technique is used. For the requirement of adequate, representative and appropriate sample size and sampling methods separate sample and sampling techniques for both (TCM and CVM) methods, i.e. the researcher used visitors which are purposely went to visit Tiya megalithic World cultural heritage (MWCH) site for TCM and the residents of Tiya town for CVM as the sampling population of the survey.

Even if, the probability sampling method is difficult for two reasons, (i), there may be no specific information about population visitors. (ii), there is limited time and budget. Since the site has an international wide market extension as well as multi-dimensional significance, it costs too much time and money to employ probability sampling method [6]. However, NOAA (National Oceanic and Atmospheric Administration) report suggested that probability sampling could be proper for accurate CVM analysis [7].

Yamane (1967) As cited by [8] provides a simplified formula to calculate sample sizes. The formula from Yamane is used to determine the minimal sample size for a given population size. This formula assumes a degree of variability of 0.5 , a confidence level of $95 \%$. Besides, in this study we used a $( \pm 0.07) \%$; level of precision to calculate the separate sample size of respondents from a total visitors 7,988
(Domestic, 5,741 and Foreign 2,247) and 670 households of Tiya town residents of 2016 (Tiya town administration and the site Tour Guide Association, 2016).

The sample size determined using Yamane's formula is:

$$
n=\frac{N}{1+N(e)^{2}}
$$

Where; $\mathrm{n}=$ sample size, $\mathrm{N}=$ population size, $\mathrm{e}=$ the level of precision

Therefore, according to the above formula the sample size estimates from 5,741 domestic visitors/ on-site survey for TCM;

$$
n=\frac{5741}{1+5741(0.07)^{2}}=197.0759 \approx 197
$$

From the total 670 households of Tiya town or community residents/ off-site survey for CVM

$$
n=\frac{670}{1+670(0.05)^{2}}=250.4672 \approx 250
$$

\subsection{Methods of Data Analysis}

The data obtained from CVM and TCM survey were analyzed using both descriptive statistics and econometrics model. Whereas, the econometrics model namely Truncated Poisson Regression (TPR) for TCM and bivariate probit model were estimated from the DBDC elicitation format for CVM.

\subsubsection{Travel Cost Method}

The study use individual travel cost (ITCM); The ITCM also avoids arbitrary zone definitions required in the ZTCM. Finally, the ITCM is better suited to provide inferences about individual consumer behavior. As a result, the ITCM gains better statistical efficiency than the ZTCM [9].

I. The Count Data Model to Estimate the Recreational Trip Demand Function

In this regard [10] provide a theoretical basis for the use of count data to model recreational demand. On any choice occasion, the decision whether to take a trip or not can be modeled with a binomial distribution. [10], as the number of choices increases, this asymptotically converges to a Poisson distribution. The density distribution for the count $\left(y_{i}\right)$ is given by:

$$
\operatorname{Pr}(Y=y)=\frac{e^{-\mu} y_{!}}{y !}, y_{i}=0,1,2
$$

Where, $\mu$ is the intensity or rate parameter. When the first two moments of this distribution equal each other $(E[Y]=$ $\mu=V[Y])$ a property known as equi-dispersion occur. This model can be extended to a regression framework by parameterising the relation between the mean parameter $\mu$ and a set of repressors $x$. An exponential mean parameterization is commonly used

$$
\mu_{i}=\exp \left(X^{\prime} \beta\right), i=1,2 \ldots \ldots, n
$$

Where $\mathrm{x}$ is the matrix of $\mathrm{k}$ regressors and $\beta$ is a 
conformable matrix of coefficients to be estimated. Given the above two equations, the Poisson regression model can be estimated, under the assumption that are independent, by maximum likelihood. According to Cameron and Trivedi (2005)[11], the assumption that the observations $\left(y_{i} \mid x_{i}\right)$ are independent, the most natural estimator is maximum likelihood. The log-likelihood function is

$$
\ln L(\beta)=\sum_{i=1}^{N}\left\{y_{i} x_{i}^{\prime}-\exp \left(x_{i}^{\prime} \beta\right)-\ln y_{i} !\right\}
$$

Given the over dispersion and endogenous stratification parameters constant, the standard regression packages can be used to estimate a Poisson model that is adjusted for truncation. In this case [12] shows that:

$$
\operatorname{Pr}[Y=y \mid Y>0]=\frac{e^{-\mu} \mu^{y-1}}{(y-1) !}, y=1,2
$$

The dependant variable (y) in this case is the number of trips which are truncated at zero, which means the number of trips is one time or more than one since only actual visitors are included. Number of trip to the site $=f$ (travel costs, travel time, demographics, site attributes, configuration variables and satisfaction after visiting). That is:

$$
\begin{aligned}
& \operatorname{NTrips}_{i j}=\beta^{\prime} X+\varepsilon_{i} \\
& \text { i. e. assumingNTrips }{ }_{i j} \mid X_{i} \sim N\left(\mu ; \sigma^{2}\right) ; \mu=\beta^{\prime} X
\end{aligned}
$$

Where NTrips ${ }_{i j}$ is individual i's trip went to site $\mathrm{j}, X_{i}$ is vector of explanatory variables, $\beta_{i}$ is a parameter vector to be estimated, and $\boldsymbol{\varepsilon}_{\boldsymbol{i}}$ is an error term.

With this functional formulation, the linear form of specification is selected after modification and estimation of all functional forms. Specifically, the equation of individual visitors demand functions for Tiya megalithic world cultural heritage site can be formulated as follows:

$$
\begin{array}{r}
\text { NTrips }_{i}=\beta_{0}+\beta_{1} S E X+\beta_{2} A G E+\beta_{3} E D U+\beta_{4} T C+\beta_{5} F S I Z E+\beta_{6} M A R S T+\beta_{7} E N V I M+\beta_{8} N G R O+\beta_{9} I N C O M+ \\
\beta_{10} K N W+\beta_{11} O C C U P+\beta_{12} H E A D H+\beta_{13} F V I S T+\beta_{14} T T R T+\beta_{15} O P W T P+\beta_{16} P P V I S T+\beta_{17} S S I T E+\beta_{18} R E L I G+\varepsilon_{i}(5)
\end{array}
$$

Where NTrips $\mathrm{s}_{\mathrm{i}}=$ the number of trips to the site by respondent ' $i$ ' in the survey year.

$\mathrm{AGE}=$ Age level, $\mathrm{SEX}=\mathrm{Sex}, \mathrm{TC}=$ Travel cost (out of pocket), EDU $=$ Education level, FSIZE $=$ Family size, MARST=Martial status for respondents, RELIG=Religion of the respondent, ENVIM=Membership in any environmental groups, $\mathrm{NGRO}=$ Number of individuals in a group tour including the respondents him/herself, INCOM=Household's monthly income, $\mathrm{KNW}=$ Previous knowledge, OCCUP=Occupation, $\mathrm{HEADH}=$ Responsibility of the respondent in the household, FVISIT $=$ Visiting for the first time or not, TTRT $=$ Total travel time, PPVIST=Purpose of Visit to the site, OPWTP=Opinion to WTP for conservation, SSITE=Number of substitute sites suggested by the respondents.

II. Estimating CS (consumer surplus)

The benefit measures associated with using the Poisson model is derive from the estimated parameter on the travel cost variable $(\beta \mathrm{tc})$, consumer surplus can be calculated by

$$
C S_{i}=1 / \beta_{t c}
$$

\subsubsection{Contingent Valuation Method}

The parametric models allow for the inclusion of covariates as explanatory variables, unlike the nonparametric [13]. The parametric analysis of response from discrete choice question is based on Random Utility Model [14]. In the RUM the observed discrete choice response of each individual is assumed to reflect a utility Maximization process. The utility arising from a 'yes' or 'no' response to the $\mathrm{CV}$ scenario of conservation/improvement of the site comprised of a deterministic component $\left(V_{j}\right)$ and $\left(\varepsilon_{j}\right)$ a random component:

$$
U_{j}=V_{j}+\varepsilon_{j}
$$

Utility is assumed to arise from income, the absence conservation/improvement and other socio-economic and demographic factors. If the household accept the offered bid its income is reduced by the bid amount \& this holds only under the following condition [14]:

$$
V_{1 j}\left(I_{j}-B_{j} ; S_{j} ; Q_{1}\right)+\varepsilon_{1 j} \geq V_{0 j}\left(I_{j}-B_{j} ; S_{j} ; Q_{0}\right)+\varepsilon_{0 j}
$$

Where $V_{1 j}$ is the in direct utility in a state of conservation/improvement $Q_{1}$ and $V_{0 j}$ is the indirect utility to the household in the absence conservation/improvement or in the status quo $Q_{0}$.

Our dependent variable is dichotomous, and equals 1 if the $j^{\text {th }}$ household is willing to pay money to support conservation program and 0 otherwise.

The general form is represented as: $Y_{j}^{*}=\beta^{\prime} X_{j}+\varepsilon_{j}$

Where, $Y_{j}^{*}$ is the dependent variable, $X_{j}$ is the vector ofindependent variables that include $\mathrm{I}$ and $\mathrm{S}$ of the above specification, $\beta$ ' is the parameter to be estimated and the random error term $\varepsilon_{j} \sim\left(0, \sigma^{2}\right) . Y_{j}^{*}$ Is a continuous latent variable $\&$ it is not observable. The observed variable is the answers 'YES' or 'NO', which can be given by a dummy variable $Y_{j}=1$ if YES and $Y_{j}=0$ otherwise, tothe question regarding whether or not the respondent will be willing to pay or willing to contribute a given bid amount. The $j^{\text {th }}$ respondent will say yes if $Y_{j}^{*}>0$ and this will be true if the condition in equation $(\mathrm{C} 2)$ is satisfied.

$$
Y_{j}=\left\{\begin{array}{c}
1 \text { if } Y_{j}^{*}>0 \text { or } V_{1 j}\left(I_{j}-B_{j} ; S_{j} ; Q_{1}\right)+\varepsilon_{1 j} \geq V_{0 j}\left(I_{j}-B_{j} ; S_{j} ; Q_{0}\right)+\varepsilon_{0 j} \mathrm{~s} \\
0, \text { otherwise }
\end{array}\right.
$$

The probability that a household $j$ is willing to pay conservation program/improvement of the site can be expressed as the difference of his/her utility functions with and without conservation / improvement of the site, i.e. 


$$
\begin{gathered}
\operatorname{Pr}_{j}(Y e s)=\operatorname{Pr}_{j}\left(Y_{j}=1\right)=\operatorname{Pr}\left(V_{1 j}\left(I_{j}-B_{j} ; S_{j} ; Q_{1}\right)+\varepsilon_{1 j}>V_{0 j}\left(I_{j}-B_{j} ; S_{j} ; Q_{0}\right)+\varepsilon_{0 j}\right. \\
=\operatorname{Pr}\left(V_{1 j}\left(I_{j}-B_{j} ; S_{j} ; Q_{1}\right)-V_{0 j}\left(I_{j}-B_{j} ; S_{j} ; Q_{0}\right)>\varepsilon_{0 j}-\varepsilon_{1 j}=F_{\eta}(\Delta V), \text { where }=\varepsilon_{0 j}-\varepsilon_{1 j}, \Delta V=V_{1 j}-V_{0 j}\right. \text { and } \\
=F_{\eta}(\Delta V) \text { isthecumulativedistributionfunction (cdf) }
\end{gathered}
$$

For the general purpose, the probability of obtaining a "yes" or "no" response for a given payment amount, Bid $_{i}$ ofconservation program/improvement can be represented as:

$$
\begin{aligned}
& Y_{j}^{*}=\beta^{\prime} X^{\prime}{ }_{j}+\varepsilon_{j}
\end{aligned}
$$

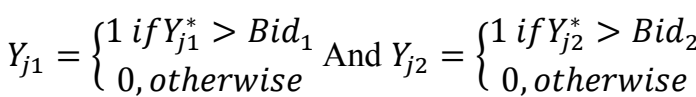

$$
\begin{aligned}
& \operatorname{Pr}_{j}(Y e s)=\operatorname{Pr}_{j}\left(Y_{j}=1\right)=\operatorname{Pr}\left(\beta X_{j}+\varepsilon_{j}>\operatorname{Bid}_{i}\right. \\
& =\operatorname{Pr}\left(\left[\varepsilon_{j} / \sigma>\left(B_{i d}-\beta X_{j} / X_{j}\right)\right.\right. \\
& =1-F\left[\left(\operatorname{Bid}_{i}-\frac{\beta X_{j}}{\sigma}\right)\right]=1-F\left(\operatorname{Bid}_{i} ; \theta\right) \\
& =1-F\left(z_{j}\right)
\end{aligned}
$$

I. Double-Bounded Models

In the double bounded dichotomous choice model for each person we have an initial bid and one follow-up bids. Thus, there are four possible outcomes: (I) both answers are "yes"; (II) both answers are "no"; (III) a "yes" followed by a "no"; and (IV) a "no" followed by a "yes".

Let the model be

$\mathrm{WTP}_{\mathrm{ij}}=\beta^{\prime} X_{i j}+\varepsilon_{i j}$ Where $\varepsilon_{i j} \sim \mathrm{N}(0, \sigma 2)$ and from equation (C5)

$$
\operatorname{Pr}(\text { yes })=1-F\left(z_{j}\right)
$$

For each respondent we have an initial bid $B_{j}^{I}$ and one of the follow-up bids, lower bid $\left(B_{j}^{L}\right)$ and higher bid $\left(B_{j}^{U}\right)$, where $B_{j}^{L}<B_{j}^{I}<B_{j}^{U}$. Each respondent will be asked arandom initial bid and the follow-up is dependent on the initial bid amount.

Following [14], the Probabilities associated with the four possible likelihood outcomes of DBDC denoted by $P(y y)$, $P(n n), P(y n)$ and $P(y n)$ for "yes, yes", "no, no", "yes, no", and "no, yes" outcomes, respectively can be presented as:

I. The probabilities for "yes, yes" outcome will be:

$$
\begin{gathered}
\mathrm{P}_{\mathrm{yy}}\left(B_{j}^{I} B_{j}^{U}\right)=\mathrm{P}\left(B_{j}^{I} \leq \operatorname{Max} . W T P a n d B_{j}^{U} \leq \operatorname{Max} . W T P\right)= \\
1-F\left(B_{j}^{U} ; \theta\right)
\end{gathered}
$$

II. The probabilities for "no, no" outcome will be:

$$
\begin{gathered}
\mathrm{P}_{\mathrm{nn}}\left(B_{j}^{I} B_{j}^{L}\right)=\mathrm{P}\left(B_{j}^{L}>\operatorname{Max} . W T P a n d B_{j}^{L}>\operatorname{Max} . W T P\right)= \\
F\left(B_{j}^{L} ; \theta\right)
\end{gathered}
$$

\section{Bivariate Probit Model}

When DBDC survey is used it is important to consider that the answer to the follow up bid is endogenous to the initial bid offered randomly. The second bid is take a predetermined value or it is not random and hence a model of joint distribution function is needed. The bivariate probit model introduced by Cameroon and Quiggin (1994) [11] has become a general parametric modeling approach for double-bounded CV survey. It is argued that the responses to the two DC questions may not be independent, but rather path dependent i.e. the response to Bid2 may be related to the response to Bid1. Sequential presentation of WTP questions (DBDC) suggests that responses to these questions might not be independent if unobserved factors influence both responses. To deal with these issues, we use a bivariate probit model to estimate preference parameters and identify correlation in the unobserved factors influencing responses across the two WTP equations. In general, a Bivariate Probit Model is specified as:

$$
\begin{aligned}
& Y_{j 1}=\beta_{1}^{\prime} X_{j 1}+\varepsilon_{j i} \\
& Y_{j 2}=\beta_{2}^{\prime} X_{j 2}+\varepsilon_{j 2}
\end{aligned}
$$

In the data $Y_{j 1} \& Y_{j 2}$ are only observable through the two discrete choice responses such that:

$$
\begin{gathered}
Y_{j 1}=\left\{\begin{array}{c}
1 \text { if } Y_{j 1}^{*}>B_{1} d_{1} \\
0, \text { otherwise }
\end{array} \text { And } Y_{j 2}=\left\{\begin{array}{c}
1 \text { if } Y_{j 2}^{*}>\text { Bid }_{2} \\
0, \text { otherwise }
\end{array}\right.\right. \\
E\left[\varepsilon_{1}\right]=E\left[\varepsilon_{2}\right]=0 \\
\operatorname{Var}\left[\varepsilon_{1}\right]=\operatorname{Var}\left[\varepsilon_{2}\right]=1 \\
\operatorname{Cov}\left[\varepsilon_{1}, \varepsilon_{2}\right]=\rho
\end{gathered}
$$

As the second equation is based on the first question response, the error terms are correlated and hence the two equations can be estimated jointly using model developed by [11], which assumes Bivariate Normal distribution for the two valuations, $B V N\left(\beta_{1} X_{1}^{\prime}, \beta_{2} X_{2}^{\prime}, \sigma_{1}^{2}, \sigma_{2}^{2}, \rho\right)$ or $B V N(0,0,1,1, \rho)$.

The two questions have four possible pairs of response: $\left(Y_{j l}\right.$, $\left.Y_{j 2}\right)=(1,1),(1,0),(0,1)$ and $(0,0)$. Combining the associated probabilities of all possible responses in the likelihood function, equation (10) can be estimated using the Bivariate Probit or the seemingly unrelated bivariate probit Model.

The censored observation are represented by infinity, but since WTP cannot exceed the disposable income of individual or cannot be negative we have asked a final open ended question on the maximum willingness to pay, thus the end points of the censored observation are constructed by incorporating the maximum WTP. [15] study (as cited by [16] in the interval data approach the probability of WTP falling between the lower and upper bounds can be specified as:

\section{$\operatorname{Pr}\left(W T P_{t} \subseteq[\right.$ Lower bound, Upper bound $\left.]\right)=$}

$\operatorname{Pr}\left(\left(\right.\right.$ lower bound $\left.-W T P_{t}\right)<z<\left(\right.$ upper bound $\left.\left.-W T P_{t}\right)\right)$ 
Where $\mathrm{z}$ is the standard normal random variable

Accordingly, in this study the double bounded interval data model (interval regression) is estimated based on equation the ML equation (C10).

Based on equation $(\mathrm{C} 11)$ and

$$
\mathrm{WTP}_{\mathrm{ji}}=\beta^{\prime} X_{j i}+\varepsilon_{j i}
$$

We have

$$
\begin{array}{r}
W T P_{j i}=\beta_{0}+\beta_{1} S E X+\beta_{2} A G E+\beta_{3} E D U+\beta_{4} B I D_{i} \\
+\beta_{5} F S I Z E+\beta_{6} M A R S T+\beta_{7} E N V I M+\beta_{8} I N C O M \\
+\beta_{9} K N W+\beta_{10} O C C U P+\beta_{11} H E A D H+\beta_{12} R E L I G+\varepsilon_{j i}
\end{array}
$$

Where $i=1,2$ i.e. 1 the first bid response is yes, 0 otherwise; 2 the second bid response is yes, 0 otherwise, $j=1$, $2,3 \ldots \mathrm{N}$

$B I D_{i}=$ is the bid price; 1 the first bid response is yes, 0 otherwise; 2 the second bid response is yes, 0 otherwise, $W T P_{j i}=\mathrm{Is}$ WTP response to the 'bid, $\beta_{j}$ is the regression parameter, $\varepsilon_{j i}$ is the error term.

\section{Descriptive and Econometric Analysis}

\subsection{Descriptive analysis}

\subsubsection{Summary Statistics of Socioeconomic Variables of TCM}

In this survey only domestic visitor were participated, because of lack of facilities (like guest house, restaurants...etc) in the site and time constraint of foreign visitors. From the total of 197 original sample respondents, only 190 were included in this analysis. The main reason for this was some respondents were reluctant to participate in the survey and their recording errors.

The average age and family size of respondents was 31.92 years and 5.4 respectively. And also the household's mean monthly income of visitors was 5,876.48 Birr. Regarding the mean total travel time and costs of the respondents, were 6.64 hours and 467.03 birr respectively to visit the site. On the other hand the average year of education of the respondent was 13.83; because of most of the respondents comes from higher institutions in groups of educational trip and the respondents under 18 years old were excluded from participation. The average number of group members was 31.57 approximately 32 persons.

\subsubsection{Summary Statistics of Socioeconomic Variables for CVM}

In this part we try to discuss some basic socioeconomic characteristics of respondents which are participated in CVM survey. Out of 250 total questionnaire only 244 used for CVM analysis. Therefore based on the survey data which is collected from Tiya town residents, the estimated average age of the respondent and the size of their household were approximately 45 years and 6 members respectively. And also the average level/years of education are 5 years. With regard to the average households monthly income and the average amount of respondents maximum WTP were $1,415.05$ and 139.35 birr respectively.

According to table 3 in the appendix 1 stated below, the percentage share of the Yes-Yes, Yes-No, No-Yes and NoNo WTP responses of the respondent for the DBDC questions were $51.64 \%, 24.59 \%, 20.08 \%$ and $3.69 \%$ respectively. The associated reason for their response is also described as; $1.23 \%$ of the respondents are not WTP at all, because they think UNESCO and the government should cover the cost and $0.82 \%$ of the respondents were WTP for the religious practice. On the other hand majority of the respondents were willing to conserve Tiya $\mathrm{MWCH}$ site for the benefit of the society $(30.33 \%)$ and next generation $(52.46 \%)$ as well as $(13.11 \%)$ for both benefits.

\subsection{Econometrics Results of Travel Cost Method}

The coefficients of total travel cost is negative which means that the higher the cost is for the trip; the lower is the visit rate to the site per year. This is consistent with expectations i.e. the demand theory, which stipulates that when the price of travel increases then the number of visits will decrease, and it is a necessary condition for the ITCM model to be valid. More specifically, the coefficient is significant at $1 \%$ confidence level. This is quite standard in the TCM literatures. Travel cost, as a price variable with negative sign is the main result of the recreation demand model, suggesting downward slopping demand curve.

\subsubsection{Determinants of Recreational Demand and Use Value of Tiya MWCH Site}

The variable Fsize (family size) of the respondents increase in the household, the probability trip frequency per year will increase. This is significant at $10 \%$ confidence level and has the unexpected negative sign. This is may depend on the wealth and employment condition of the household, The dummy variables Ppvis (purpose of visit) and Fvist (first visit) are significant at $1 \%$ confidence level but in reverse effects. Ppvis has positive and significant effects to the number of trip i.e. the visitor that comes for recreational purpose repeatedly than educational and others. The other significant variable is Opwtp (opinion to WTP) which have negative effect to number of trip to the site. Since it is the monetary contribution (proxy to cost) and increase the cost of the visit; the more willing to pay the visiting per year to the site.

\subsubsection{Recreational Benefit Estimation of Tiya MWCH}

To calculate recreational benefit (the use value), a simple demand function can be estimated by using the coefficients and the mean values of significant variables reported in appendix 2 table 4 the estimated demand function is:

$$
\text { NTrips }=2.968254-0.001385 \mathrm{TC}
$$

From the estimated regression equation, expected number of trip is calculated equal to 2.321054 per year on average. The benefit measures associated with using the Poisson model will derive from the estimated parameter on the travel cost variable $\left(\beta_{\mathrm{tc}}\right)$; consumer surplus can be calculated by 


$$
C S_{i}=721.60485 \text { per trip }
$$

Formally, based on two equations above, the consumer surplus is equal to: individual per trip CS multiplied by the average annual trip that was $721.60485 * 2.321054=1,674.8838$

\subsection{Aggregation of Benefit to the Site}

Total recreational benefit of Tiya MWCH site is computed by multiplying individual consumer surplus by the annual number of visits. With the total number of visitors to the site of 5,741 (Tiya town administration and the site Tour Guide Association, 2016), then the total recreational benefit is estimated to be 9,615,508.00 ETB per year.

Determination of Optimum Entrance Fee

The maximum entrance fee that can be charged depends on how responsive the trip demand function is to price changes (i.e. travel cost).

Let Ntrips $=\mathrm{N}$ and $\mathrm{TC}=\mathrm{P}$, then from the given equation, $\frac{\Delta N}{\Delta P}=\frac{\partial N}{\partial P}=-0.0013858 \approx \frac{\partial N}{\partial F}$

Where $F=$ is the entrance fee per annum.

Now using the individual function above and the trip elasticity of entrance fee, the following table is displays the various elasticity at different annual entrance fees and number of days spent on site.

\subsection{Econometric Results of Contingent Valuation Method}

\subsubsection{Estimation of the Willingness to Pay for the Nonuse Value of Tiya MWCH Site}

In this section we analyzed and present the results of CVM from double bounded dichotomous questions using bivariate probit model.

I. Double-Bounded Models
To Model Responses from the DBDC CV survey we have estimated variants of double bounded models which are including the bivariate probit model proposed by [11] and the interval-data model proposed by [14].

In order to choose the appropriate model, we need to see the rho value estimated for the bivariate probit model measures the correlation between the error terms from the two response equations, taking on a value between -1 and 1 , where -1 indicates perfect negative correlation, zero indicates that the responses are separately determined, and 1 indicates perfect joint-determination.

Therefore value of rho for the bivariate probit model is .0776519 for the full model including covariates. This indicates the use of bivaraite probit instead of interval data model is more appropriate. More over the Wald test of rho $=0$ shows that the correlations between the two error terms are statistically different from Zero at $1 \%$ level of significance and leads to choose of Bivaraite probit model

II. Bivariate Probit Model

Based on the bivariate probit model regression, Table 1 shows the effects of the first bid prices answers or WTP for some of the basic socio demographic characteristics of the respondents are significantly affect the WTP function. Among these variables AGE, HEAD (being head of the household) and INCOM (monthly income of the household), ENVIM (membership in environmental group) and KNW (previous knowledge to the site) are having the expected sign and positive effect. And also the variables FSIZE (family size), the first bid price (BID1) and second bid price (BID2) having the expected sign and negative effect to wiliness to pay. Whereas EDU or education level of the respondents is unexpectedly having negative effect to the demand for conservation or willingness to pay.

Table 1. Estimated Coefficients from Double-Bounded Models (Bi-varaite probit model, robust).

\begin{tabular}{|c|c|c|c|c|}
\hline Variable & Coefficient & Robust Std. Err. & $\mathbf{P}>|\mathbf{z}|$ & Marginal effect \\
\hline \multicolumn{5}{|l|}{ wtp1 } \\
\hline age & $.0358523 *$ & .0199417 & 0.072 & .0000208 \\
\hline $\operatorname{sex} *$ & .5455745 & .4181763 & 0.192 & -.036919 \\
\hline marst* & -.2486632 & .3215644 & 0.439 & .0428577 \\
\hline fsize & $-.3166747 * * *$ & .1103253 & 0.004 & -.003207 \\
\hline relig* & -.3620267 & .3091594 & 0.242 & .0914889 \\
\hline headh* & $.5662266^{*}$ & .3172039 & 0.074 & .0106851 \\
\hline occup* & .6464511 & .4128103 & 0.117 & .142271 \\
\hline incom & $.0004427 *$ & .0002339 & 0.058 & .0001772 \\
\hline envim* & $1.217025 * * *$ & .4009229 & 0.002 & .1503473 \\
\hline knw* & $.7783414 *$ & .4033098 & 0.054 & .0451592 \\
\hline bid1 & $-.0783803 * * *$ & .0153791 & 0.000 & .0000269 \\
\hline bid2 & $.0674832 * * *$ & .0107398 & 0.000 & .0020426 \\
\hline _cons & -.1773376 & 1.132621 & 0.876 & \\
\hline rho & -.0776519 & .2385387 & -.4991489 & .3735607 \\
\hline \multicolumn{5}{|c|}{ Number of obs $=244$} \\
\hline \multicolumn{3}{|c|}{ Log pseudo likelihood=-134.59551 } & \multicolumn{2}{|l|}{$\mathrm{R}^{2}=51.2 \%$} \\
\hline \multicolumn{3}{|c|}{ Wald $\operatorname{chi} 2(26)=122.95$ Prob $>$ chi $2=0.0000$} & \multicolumn{2}{|c|}{$y=\operatorname{Pr}(w \operatorname{tp} 1=1$, wtp $2=1)=0.76717811$} \\
\hline \multicolumn{3}{|c|}{ Wald test of rho $=0: \operatorname{chi} 2(1)=0.105119$} & \multicolumn{2}{|c|}{ Prob $>$ chi $2=0.7458$} \\
\hline
\end{tabular}

Source: Model estimation based on survey data.

Source: Model estimation based on survey data.

Note that: $* * *=1, * *=5$ and $*=10$ percent level of significance respectively: Std. Err (robust standard error).

$(*)$ on the head of the variables is $\mathrm{dy} / \mathrm{dx}$ for discrete change of dummy variable. 
Table 1 shows that, the first bid and second bid prices as expected previously are found to be the main variable that affects WTP and significant at $1 \%$ level of significance. this shows, if bid price increases, then the probability of the respondent's willingness to pay for the conservation of the site (Tiya MWCH site) will decreases, citrus paribus. Therefore, any change in bid price will have an inverse effect on the first WTP.

The coefficient of respondent's household monthly income is positive and expected to affect respondent's WTP answer positively. It is significant at $10 \%$ and $1 \%$ for first and second WTP answers respectively. An increase in the monthly income of an individual increases, his/her willingness to pay for the nonuse value part of the site will increase.

The other significant socio-demographic variables AGE and HEADH have positive effect as expected and significant at $10 \%$. As the age of the respondents increase the probability of supporting the conservation program is also increase. On the other hand having the more responsibility (being head of the household) of the respondents in the family is the more willing to pay to protect this world cultural heritage site of Tiya.

On the other hand, the variable FSIZE (family size) of the respondents increase in the household, the probability of willingness to pay will decrease. This is significant at $1 \%$ confidence level and has the expected negative sign.

Unexpectedly, as shown in Table 1 above, the level of education of the respondents has negative sign and significant at $1 \%$ confidence level. Negative relationship between WTP and education could be anticipated in some cases, as more educated respondents are likely to engage more critically with the scenario presented to them in the hypothetical market and more likely to refuse for WTP. More educated respondents are more likely to be familiar with such reasons [12], But in our case, may the reverse is true. Because of two reasons i.e. the nature of the good and the nature of the sample respondent may force us to accept the result. Since the good is cultural heritage which have log age and the respondents are residents of its surroundings as well as majority of them are illiterate, they are highly concerned about their cultures as well as cultural heritages. As a result they considered this cultural heritage inherited as a bequest from their fathers belongs to their children and also as their symbol of identity, therefore they are highly willing to pay to conserve the cultural heritage site of Tiya. Instead the more educated the respondents having less concerning or reluctant to cultural things and practices due to the influence of modernization; therefore they have less WTP for such goods. But it needs further investigation and justification.

The other significant variable is (ENVIM) member of any of the environmental groups are more likely willing to pay at $1 \%$ level of significance. In this regard most of the respondents state that they are a member of soil and forest conservation in community level government organization frameworks and in school clubs. This result may be attributable to their knowledge on environmental protection and resource conservation and hence attach more value to this kind of cultural heritages than those who are not a member of environmental groups.

The respondents who have Knowledge about the site (KNW), it is important determinants of WTP of most cultural heritages like Tiya and it is significant at $10 \%$. That is, an individual has the more the number of years and information about the site; they are more willing to pay to conserve this prestigious cultural heritage site.

\subsubsection{Summary of WTP Estimates}

The main reliability of econometric model is that, It describes the decisions how to achieve or (how to know) concerning to estimate the average WTP in the population. The mean WTP estimation was made using the two WTP bid price answers or actual ability to pay. The estimation was conducted in two steps. The first step was estimation of the model. The second step is finding the mean WTP. To estimate the mean WTP the survey resort to simulating confidence intervals with the Krinsky Robb procedure. The Krinsky Robb method uses random draws from assumed multivariate normal distribution to generate new parameter vectors. Based on this, the estimate of Krinsky Robb method is presented in table 2 below.

Table 2. Estimation of Mean Willingness to Pay of the Respondents.

\begin{tabular}{llllll}
\hline \multicolumn{1}{l}{ Krinsky and Robb (95\%) } & Confidence Interval for WTP Measures (Nb of reps: 5000) & & \\
\hline MEASURE & WTP & LB & UB & ASL $^{*}$ & CI/MEAN \\
\hline MEAN/MEDIAN & 96.26 & 85.65 & 116.68 & 0.0000 & 0.32 \\
\hline
\end{tabular}

Source: Source: model estimation based on survey data.

*: Achieved Significance Level for testing H0: WTP $<=0$ vs. H1: WTP $>0$.

LB: Lower bound; UB: Upper bound.

Therefore based on the estimate of Krinsky Robb method the average or mean WTP of the sample respondents is 96.26 birr for a one time contribution.

\subsubsection{Aggregation of WTP}

The aggregation of WTP for the attainment of conservation target, the representative sample respondents WTP values summarized in Table 2 must be aggregated across the relevant population $[7,17]$. Besides this, the population of interest to this study is defined as 670 households of Tiya town residents ${ }^{1}$. As a result, the estimate of the aggregate WTP of the population or the nonuse value of Tiya megalithic world cultural heritage site is $64,494.20$ birr for a one time contribution.

1 Tiya town administration and the site Tour Guide Association, 2016). 


\section{Conclusion and Recommendations}

\subsection{Conclusion}

The main objective of this study was to analyze and estimate the total economic value of Tiya megalithic world cultural heritage site using the most commonly known and applicable non market valuation techniques of TCM and CVM.

The value of this cultural heritage resource i.e. Tiya megalithic world cultural heritage site was illustrated using the Demand models. As a result, the use value of the site is estimated from data collected through the TCM, which helped to find the current recreational benefit Also the nonuse value part is estimated from the CVM.

The TCM counted data model regression analyses results, most of the estimated coefficients of variables have the expected signs. The characteristics of the respondent such as, family size, head of household, household monthly income, and knowledge about Tiya MWCH site are all significant and have a positive effect on the number of trips to the site. Similarly, memberships in any environmental group and visitor's visiting purpose are also significant and have positive impact on the number of trips to the site. On the other hand, variables such as SEX, opinion to WTP or conservation program, visit for the first time, total cost, and total travel time are significant and have negative impact on the number of trips to the site.

According to the CVM survey analysis of bivariate probit model regression, the effects of the first bid prices answers or WTP. Among these variables age, being head of the household and monthly income the household, membership in environmental group and previous knowledge to the site are having the expected sign and positive effect on WTP. And also the variables family size, the first bid price and second bid price having the expected sign and negative effect to wiliness to pay. Whereas education level of the respondents is unexpectedly having negative effect to the demand for conservation or willingness to pay.

As estimated by the count data model, the study found the mean consumer surplus per individual to be 1,674.88 ETB per year. This surplus represents only one category of total recreational value (i.e. only from domestic visitors). And the total use value of the site is approximately estimated to be 9,615,508.00 ETB per year and also ETB 1070.85 was the average entrance fee per annum which maximizes the total revenue.

On the other hand, Maximum likelihood estimation analysis from the DBDC bivarite probit model which employed to derive CVM survey demand function of community residents Willingness to pay for the non-use value part of Tiya MWCH site is found to be affected by the first bid levels, and monthly income of the respondents. As a result, the mean WTP of the sample respondents for the conservation of Tiya $\mathrm{MWCH}$ site by using Krinsky Robb method on average it is 96.26 birr for a one time contribution. And also the total nonuse value of Tiya megalithic world cultural heritage site is $64,494.20$ birr for a onetime contribution from community residents only.

Therefore the total economic value of Tiya MWCH site is found by the sum of the use value and the nonuse value of the site. Based on the above finding the use value contribution was estimated to be 9,615,508.00 ETB and also the nonuse value is $64,494.20$ ETB.

\subsection{Recommendations}

In the current economic development strategies, the competitiveness of the tourism sector of countries is one of the major concerns of economist. Among the basic pillars of tourism sector development, cultural heritage is the front runner. In line with the findings of this study, the following recommendations are forwarded.

First, the stakeholders of cultural heritage sites and associated communities should be engaged in development and implementation of different programs. It is necessary to have them realize the importance and perceive the genuine value of the site, which is located in their own province. This is extremely worth doing because this study revealed that residents which have knowledge about Tiya MWCH site will be willing to pay more for good-quality heritage.

Second, there is a need to improve the facilities around the site so that visitors can extend the number of days they can stay there and hence spend more. Also the rate of re-visitors to the site will increase. This would in turn enable the relevant authorities and the community business organizations to increase the revenue obtained from the sector.

Thirdly, the responsible body should makes functional the museum and associations that works around the site in order to provide appropriate services create job opportunities and generate more revenue from the site.

Fourthly, review and determine the optimal entrance fee, conduct continuous monitoring and staff's training are appropriate in order to acquire more revenue from the visitors that access Tiya MWCH site.

Finally the Government or the Ministry of Culture and Tourism should pay attention and setting specific responsible and accountable body and create appropriate management plan and efforts should be made to improve monitoring of the site by local authorities and make the site so gorgeous by thinking about the future benefit. 


\section{Appendix}

\section{Appendix 1 Descriptive response of CVM Survey Analysis}

Table 3. Other Descriptive Statistics of CVM Survey Analysis (observation, 244).

\begin{tabular}{|c|c|c|c|}
\hline Description & Response & Frequency & Percent (\%) \\
\hline \multirow{5}{*}{$\begin{array}{l}\text { WTP responses for the } \\
\text { DBDC questions }\end{array}$} & Yes-Yes & 126 & 51.64 \\
\hline & Yes-No & 60 & 24.59 \\
\hline & No-Yes & 49 & 20.08 \\
\hline & No-No & 9 & 3.69 \\
\hline & Total & 244 & 100.00 \\
\hline \multirow{7}{*}{$\begin{array}{l}\text { Reasons for their willingness } \\
\text { to pay of the respondent }\end{array}$} & Not WTP & 3 & 1.23 \\
\hline & My own benefit & 3 & 1.23 \\
\hline & For the next generation & 128 & 52.46 \\
\hline & For religious practice & 2 & 0.82 \\
\hline & for the society benefit & 74 & 30.33 \\
\hline & others & 2 & 0.82 \\
\hline & Both for the society and next generation & 32 & 13.11 \\
\hline \multirow{6}{*}{ Payment Vehicle/mechanism } & Not WTP & 3 & 1.23 \\
\hline & Bank system & 29 & 11.89 \\
\hline & Entrance fee & 3 & 1.23 \\
\hline & Cash & 206 & 84.43 \\
\hline & Tax system & 3 & 1.23 \\
\hline & Total & 244 & 100.00 \\
\hline \multirow{3}{*}{$\begin{array}{l}\text { Previous Visiting experience } \\
\text { of the respondents }\end{array}$} & No & 63 & 25.82 \\
\hline & Yes & 181 & 74.18 \\
\hline & Total & 244 & 100.00 \\
\hline \multirow{3}{*}{$\begin{array}{l}\text { Visits of the respondent if the } \\
\text { site is improved }\end{array}$} & No & 18 & 7.38 \\
\hline & Yes & 226 & 92.62 \\
\hline & Total & 244 & 100.00 \\
\hline
\end{tabular}

Source: Own computation based on survey data.

\section{Appendix 2 Coefficients Reported by DBDC Biviriate Probit Model for CVM}

Table 4. Maximum Likelihood Estimation of Truncated Poisson Regression Model (Robust).

\begin{tabular}{|c|c|c|c|c|}
\hline Variable & Coefficient & Robust Std. Err. & Marginal effect & Mean \\
\hline Age & .0062787 & .0078054 & .0057999 & 31.92105 \\
\hline Sex* & $-.3738079 * * *$ & .1453724 & -.4152005 & 0.6 \\
\hline Marst* & -.086291 & .1014401 & -.0893478 & 0.5157895 \\
\hline Fsize & $.0624118^{*}$ & .0321962 & .0656959 & 5.431579 \\
\hline Headh* & $.5364782 * * *$ & .145768 & .6407135 & 0.3263158 \\
\hline Relig* & -.1145487 & .0751585 & -.126056 & 0.6842105 \\
\hline Occup* & -.136175 & .0831335 & -.1364813 & 0.5105263 \\
\hline Incom & $.0000309 *$ & .0000166 & .0000347 & 5876.484 \\
\hline Envim* & $.1505499 *$ & .0894392 & .1688535 & 0.1947368 \\
\hline $\mathrm{Knw}^{*}$ & $.2893959 * *$ & .1436133 & .2740701 & 0.8105263 \\
\hline Ppvis* & $.3058908 * * *$ & .1111866 & .3575342 & 0.2421053 \\
\hline Ttrt & $-.0344893 *$ & .0196313 & -.0339058 & 6.640211 \\
\hline Fvist* & $-2.551849 * * *$ & .9448189 & -2.0094 & 0.2789474 \\
\hline Ssite* & -.0575869 & .0702554 & -.0566723 & 0.4263158 \\
\hline Opwtp* & $-.3269835^{* * *}$ & .0970914 & -.43325 & 0.8842105 \\
\hline $\mathrm{TC}$ & $-.0006374 * * *$ & .0002305 & -.0006959 & 467.0343 \\
\hline constant & .7235356 & .3026377 & $\mathrm{~N} / \mathrm{A}$ & N/A \\
\hline \multicolumn{2}{|c|}{ Number of obs $=190$} & \multirow{2}{*}{ Pseudo R2 $=0.2899$} & Wald chi $2(18)=$ & \\
\hline \multicolumn{2}{|c|}{ Log pseudo likelihood=-208.15102 } & & Prob $>$ chi $2=0.0$ & \\
\hline
\end{tabular}

Model estimation based on survey data. 
Bivariate probit regression

Log pseudolikelihood $=-134.59551$

Number of obs $=$
Wald chi2(26)
Prob $>$ chi2 $=$

244

122.95

0.0000

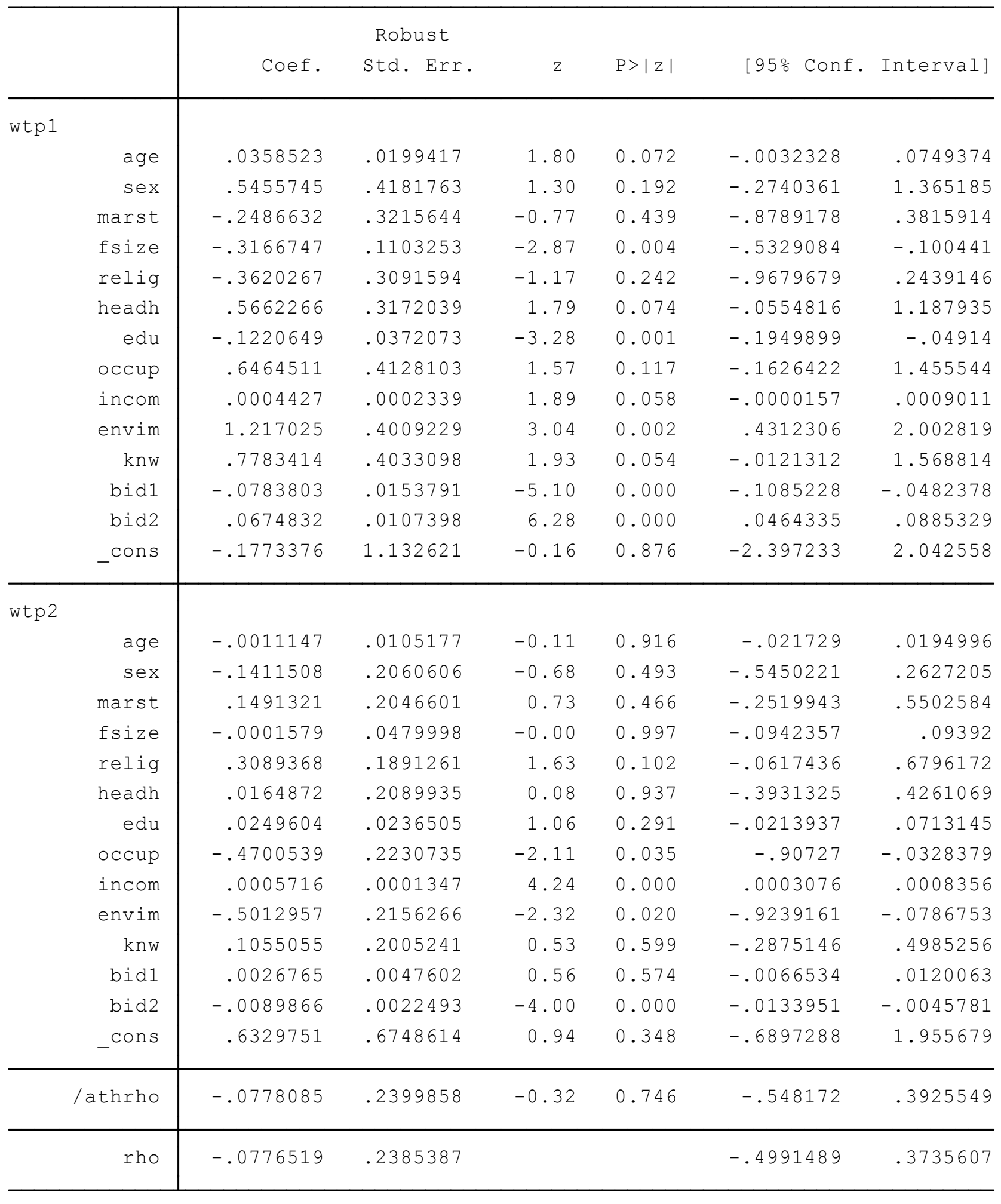

Wald test of $r h o=0$ :

$\operatorname{chi2}(1)=.105119$

Prob $>$ chi2 $=0.7458$

Figure 2. Response of Bivariate Probit Model for CVM. 


\section{Appendix 3 Optimum Entrance Fee at Maximum Revenue}

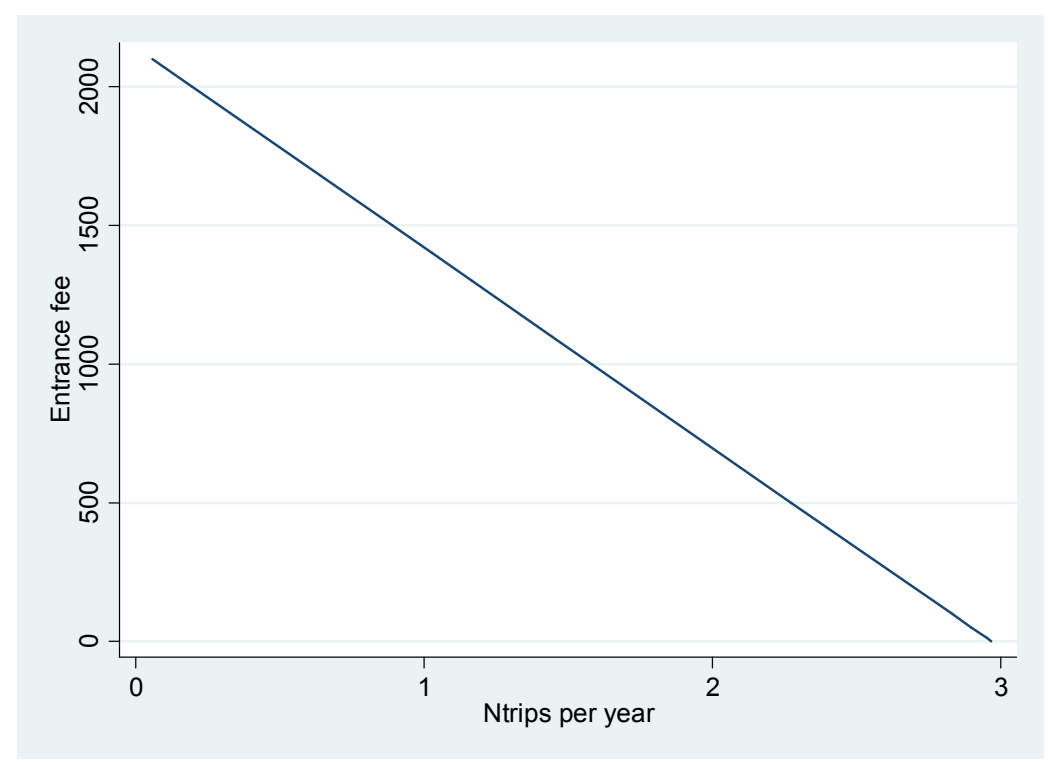

Source: model estimation.

Figure 3. Entrance Fee at Maximum Revenue.

\section{References}

[1] World Economic Forum, The Travel \& Tourism Competitiveness Report 2015, vol. 44, no. October. 2015.

[2] K. Perera, "The Role of Museums in Cultural and Heritage Tourism for Sustainable Economy in Developing Countries Kamani," Anim. Genet., vol. 39, no. 5, pp. 561-563, 2008.

[3] S. Akhter, T. S. Yew, and F. P. Studies, "GREENER JOURNAL OF ECONOMICS AND ACCOUNTANCY Tourists 'Willingness to Pay for Marine Resource Conservation at Pulau Perhentian Marine Park, Malaysia," no. 2010, pp. 2354-2357, 2018.

[4] E. Avrami and R. Mason, "Heritage Values and Challenges of Conservation Planning," Management Planning for Archaeologial Sites. pp. 13-26, 2000.

[5] S. Navrud, "Valuing cultural heritage - Lessons learned," WIT Trans. Built Environ., vol. 83, pp. 95-100, 2005.

[6] P. Wu and I. Introduction, "Design of an Efficient and Complete Elicitation Decision Process in Contingent Valuation Method : Benefit Evaluation of Kengting National Park in Taiwan Ming-Ta Su II. Theoretical Framework of Benefit Evaluation for National Park 2. 1 Willingness to Pay for the Resources of the Park," pp. 1-21, 1996.

[7] P. Breve et al., "Report of the NOAA panel on Contingent Valuation Report of the NOAA Panel on Contingent Valuation Kenneth Arrow Robert Solow Paul R. Portney Howard Schuman," no. October 1999, pp. 11-30, 2017, doi: 10.13043/DYS.79.6.

[8] A. Singh and M. Masuku, "Sampling Techniques \& Determination of Sample Size in Applied Statistics Research: an Overview," Ijecm. Co. Uk, vol. II, no. 11, pp. 1-22, 2014.

[9] J. M. Bowker and V. R. Leeworthy, "Accounting for ethnicity in recreation demand: A flexible count data approach," J. Leis. Res., vol. 30, no. 1, pp. 64-78, 1998, doi: 10.1080/00222216.1998.11949819.

[10] T. Haab and K. McConnell, "Valuing Environmental and Natural Resources. The Econometrics of Non-Market Valuation. New Horizons in Environmental Economics, Wallace E. Oats and Henk Folmer (Ed. s). Edward Elgar Publishing limited.," pp. 1-21, 2002, doi: $10.4337 / 9781843765431$.

[11] C. Cameron and P. Trivedi, "Regression Analysis of Count Data (Econometric Society Monographs)," no. 30, pp. 96-137, 1998, doi: 10.1017/CCOL0521632013.

[12] H. Bakhshi, D. Fujiwara, R. Lawton, S. Mourato, and P. Dolan, "Measuring Economic Value in Cultural Institutions A report commissioned by the Arts and Humanities Research Council's Cultural Value Project," p. 104, 2015.

[13] A. Alberini, B. Kanninen, and R. T. Carson, "Modeling response incentive effects in dichotomous choice contingent valuation data," Land Econ., vol. 73, no. 3, pp. 309-324, 1997, doi: $10.2307 / 3147170$.

[14] M. Hanemann, J. Loomis, and B. Kanninen, "Statistical Efficiency of Double-Bounded Dichotomous Choice Contingent Valuation," Am. J. Agric. Econ., vol. 73, no. 4, pp. 1255-1263, 1991, doi: 10.2307/1242453.

[15] R. C. Mitchell, "Using Surveys to Value Public Goods," Using Surv. to Value Public Goods, pp. 7-9, 2013, doi: $10.4324 / 9781315060569$.

[16] D. J. Maddison and S. Mourato, "by David Maddison and CSERGE Working Paper GEC 99-08," no. May, 2014, doi: $10.1179 / 135050301793138182$.

[17] A. Alberini et al., "Modeling Response Incentive Effects in Dichotomous Choice Contingent Valuation Data," vol. 73, no. 3, pp. 309-324, 1997. 